\title{
Mitral valve replacement with mounted aortic valve homografts
}

\author{
M. A. ROGERS, R. J. CHAMBERS, M. S. GOTSMAN, \\ and W. S. WINSHIP
}

Thoracic and Cardiology Units, Wentworth Hospital, University of Natal

The clinical results of isolated mitral valve replacement with mounted aortic valve homografts undertaken in 29 patients is presented. In 15 of these patients haemodynamic evaluations were made before and after operation. The results attest to the haemodynamic suitability of the homograft aortic valve in the mitral position and it would appear from this initial study that there will be little difference in the durability of orthotopic and heterotopic aortic homograft valves.

Experience over the past eight years with transplantation of aortic valve homografts to the subcoronary position has clearly demonstrated their advantages. Unlike mechanical prostheses the homograft aortic valve permits unobstructed central flow ; thromboembolic complications are rare and homograft valve failure of any variety is not a cause of sudden death (Barratt-Boyes and Roche, 1969). Late homograft valve failure is currently confined to leaflet rupture which is related to the method of preparation of the homograft. Methods of sterilization and storage which do not damage the mucopolysaccharides, collagen, and elastin that make up the leaflet should improve the durability of the homograft, and the present method of antibiotic sterilization may achieve this.

Despite the advantages of homograft valves there have been few reports describing the use of aortic valve homografts for mitral valve replacement (Yacoub and Kittle, 1969; Angell, Wuerflein, and Shumway, 1967 ; Watson et al., 1968 ; Angell, Iben, Gianelly, and Shumway, 1969 ; Bigelow, Trimble, Auger, and Wigle, 1967 ; Angell, Stinson, Iben, and Shumway, 1968 ; Hubka, Siška, and Holec, 1967). The average human aortic valve area is $2.8 \mathrm{~cm}^{2}$, which is well above the critical mitral area of 1 to $1.5 \mathrm{~cm}^{2}$. Normal cardiac output can be maintained through the average size aortic valve in the mitral annulus without significant elevation of the left atrial pressure. The size difference between aortic and mitral valves is, therefore, not a deterrent.

Isolated mitral valve replacement using mounted aortic valve homografts has been undertaken in 29 patients. Clinical and haemodynamic evaluations made before and after mitral valve replacement with mounted aortic valve homografts form the basis of this report.

\section{METHOD OF PREPARATION}

Homografts are collected from unselected routine necropsies, preferably from young subjects, and within 24 hours of death. The details of age and time and mode of death are documented in relation to each graft. The valves are examined macroscopically and a simple test of tear-out strength is made on the aortic wall adjacent to the valve- $3 / 0$ atraumatic sutures are placed $3-5 \mathrm{~cm}$ from the cut edge and subjected to a stress of $350 \mathrm{~g}$ (Ross, 1968). Unsuitable valves are discarded. The graft is trimmed in a circular fashion at both ends, leaving a skirt of endocardium and mitral valve below the aortic cusps on the ventricular side and $2 \mathrm{~mm}$ of aortic wall above the top of each commissure. Lusterlite ${ }^{1}$ titanium frames covered with a single layer of 50 denier Dacron with an internal diameter of $26,28,30$ or $32 \mathrm{~mm}$ are used for mounting the homograft. The graft is placed inside a frame of appropriate size so that the graft is slightly too large for the ring, to ensure that the cusps will hang in a natural way without stretching or distortion after fixation. A holding mattress suture is placed through the apex of each commissure and the apex of the ring. The graft and the ring are turned upside down and attention is directed to the lower edge which is trimmed in a circular fashion to fit the ring. The aortic wall is cut away so that the free edge approximates the upper edge of the ring, to which it is sutured with a running stitch. The mounted valve is tested under a pressure of $200 \mathrm{mmHg}$. If there is no distortion of the cusps

1Lusterlite Products Limited, 56 Devon Road, Leeds 2 


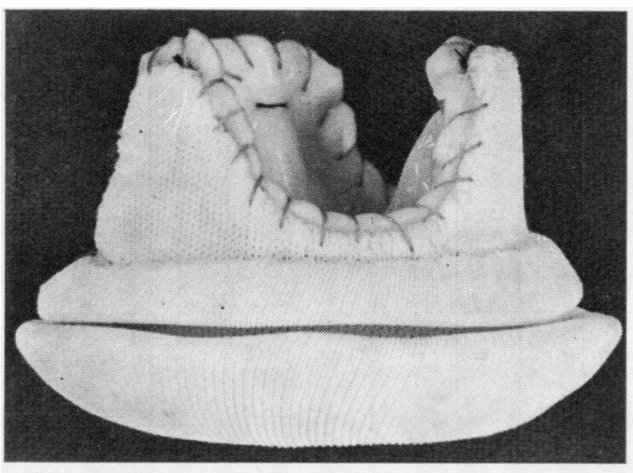

(a)

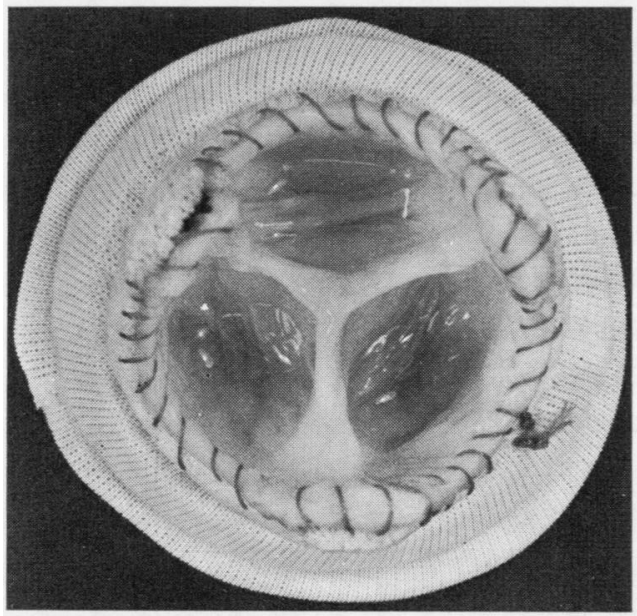

(b)

FIG. 1. Mounted aortic valve homograft views (a) in profile, and (b) from the ventricular aspect.

and they remain competent, the graft is then sterilized (Fig. 1a, b).

Initially, the mounted valves were sterilized in $12 \%$ ethylene oxide in $88 \%$ Freon at a pressure of $26 \mathrm{lb} / \mathrm{in}^{2}$ $(1.793 \mathrm{bar})$ at $39.2^{\circ} \mathrm{F}\left(4^{\circ} \mathrm{C}\right)$ for 24 hours and then flash frozen to $-110.2^{\circ} \mathrm{F}\left(-79^{\circ} \mathrm{C}\right)$ for storage. Latterly, the valves have been sterilized in an antibiotic mixture.

\section{CLINICAL EXPERIENCE}

Isolated mitral valve replacement has been undertaken on 29 patients-20 females and 9 males. Their ages ranged from 9 to 50 years. Nine patients had previously had an operation on the mitral valve ; in five, a closed mitral valvulotomy had been performed while four had undergone mitral valve annuloplasty. All but one patient had rheumatic heart disease. Three children in this series had active rheumatic carditis at the time of valve replacement, the operation being done as a life-saving procedure. The diagnoses were established by cardiac catheterization and verified at operation. Five patients had calcific mitral stenosis; the remainder had mixed mitral valve disease. All patients fell into class III or IV of the New York Heart Association classification.

There has been one death in this series, 12 hours after operation. The cause of death was obstruction of the endotracheal tube-an avoidable death not related to the function of the homograft. One patient sustained a cerebral embolus at operation. This was probably due to calcium debris from a heavily calcified mitral valve and has left the patient with a permanent neurological deficit. One patient required reexploration in the immediate postoperative period for the management of cardiac tamponade.

The 28 survivors have now been followed for periods ranging from 6 to 24 months (Fig. 2). Valve failure, persistent mitral regurgitation, and cardiomyopathy accounted for poor results in three patients. These patients are discussed in detail below.

The remaining 25 patients have shown marked clinical improvement. They are in class I or II of the New York Heart Association classification. This group includes two children who have evidence of continuing rheumatic carditis.

Bacterial endocarditis has not occurred and there have not been thromboembolic episodes. Anticoagulants were administered for three

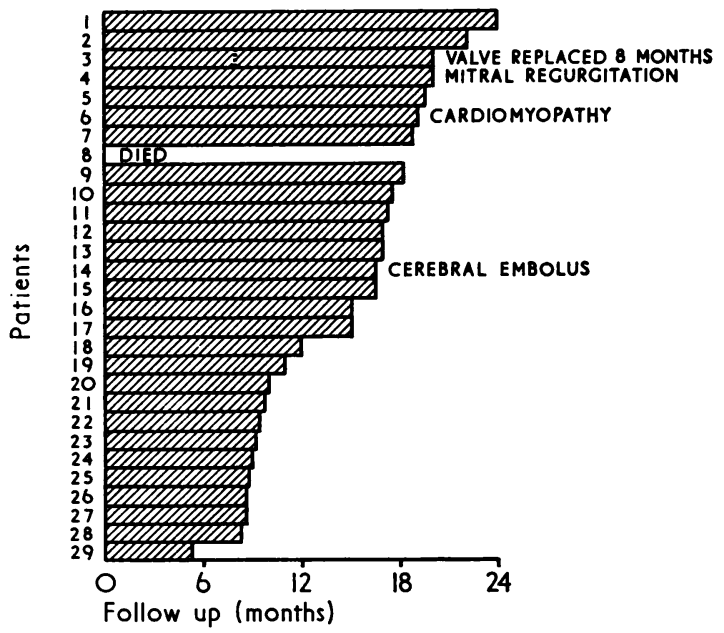

FIG. 2. Length of follow-up and complications in the 29 patients who underwent homograft aortic valve replacement of the mitral valve. 
量

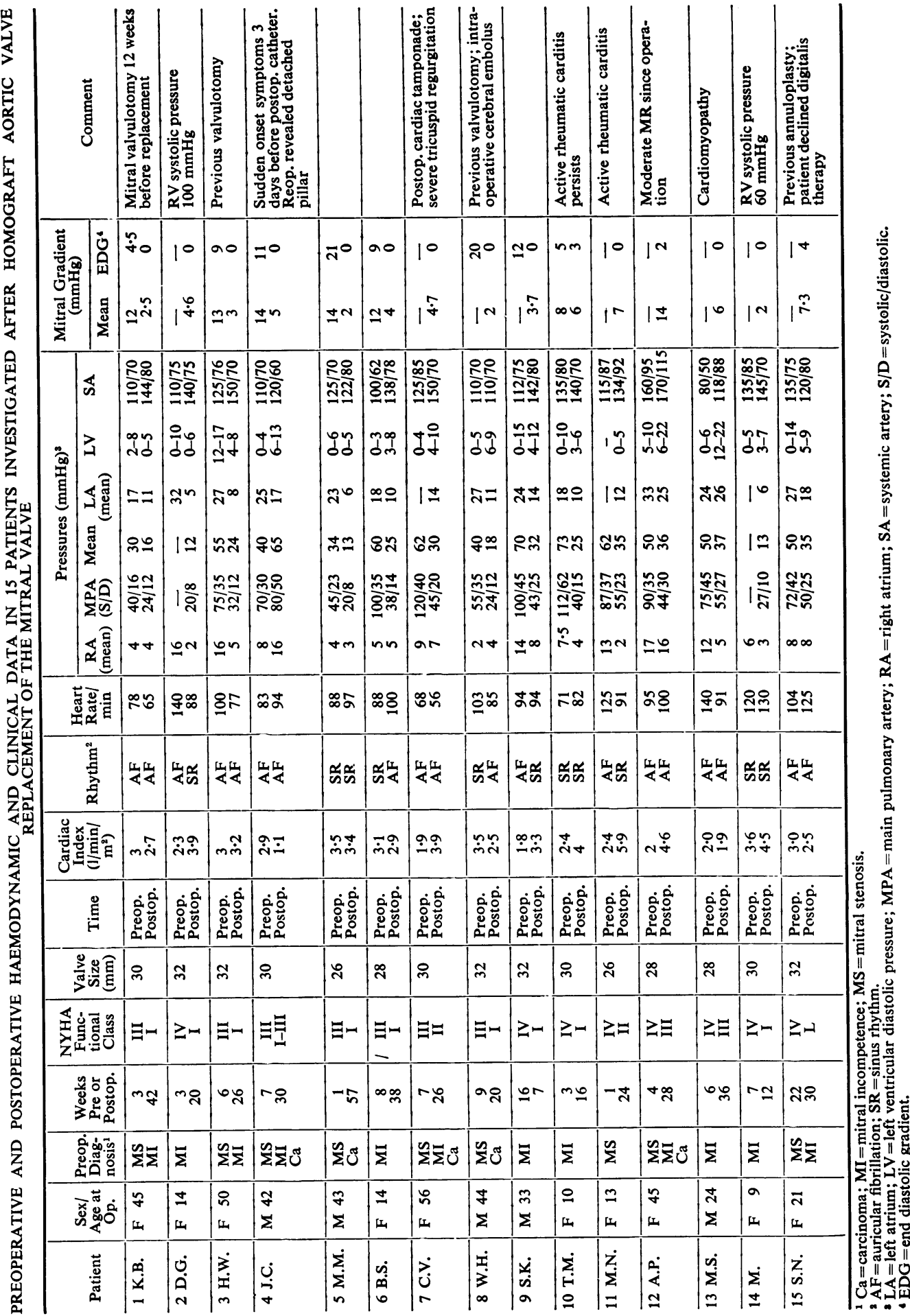


months to one patient only who had a large ball thrombus removed from the left atrium, leaving behind a shaggy left atrial wall.

\section{HAEMODYNAMIC ASSESSMENT OF MOUNTED HOMOGRAFT VALVES}

Of the 28 patients who survived homograft mitral valve replacement, 15 were studied by cardiac catheterization and angiography 7 to 57 weeks after operation. Clinical assessment of 12 patients indicated a normal functioning valve, and investigation was performed with the full knowledge and consent of each patient to assess the haemodynamics of the valve at rest. Three patients failed to show the expected clinical improvement, and investigation was performed to establish the cause ; important mitral regurgitation was present in two, and the remaining patient persisted in severe cardiac failure despite vigorous therapy and the absence of mitral regurgitation. The haemodynamic data of all 15 patients are shown in the Table.

NORMAL FUNCTIONING VALVES In the 12 patients with clinically normal valves, the mean left atrial pressure fell from the preoperative average level of 23.6 (range 17-32) $\mathrm{mmHg}$ to 10.3 (range 5-18) $\mathrm{mmHg}$. Only one patient had a raised left atrial pressure of $18 \mathrm{mmHg}$ (Fig. 3a). The average mean gradient across the homograft valve was 4 (range 2-7.3) $\mathrm{mmHg}$, and two patients had an end-diastolic gradient across the valve of 3 and $4 \mathrm{mmHg}$ respectively. The remaining 10 patients showed no gradient at end-diastole at resting heart rates between 65 and 130 beats/minute. The patient with the raised left atrial pressure of $18 \mathrm{mmHg}$ had a mean mitral valve gradient of $7.3 \mathrm{mmHg}$ and an end-diastolic pressure gradient of $4 \mathrm{mmHg}$; these pressures were recorded at a resting heart rate of $125 /$ minute, and this was considered a contributory factor in the production of mild mitral stenosis. This patient persistently declined digitalis therapy, and her heart rate during normal activity about the ward was $150 /$ minute. Parallel with the reduction of left atrial pressures to normal the average mean preoperative pulmonary artery pressure of 53.6 (range $30-73$ ) $\mathrm{mmHg}$ fell to $25 \cdot 3$ (range 13-35) $\mathrm{mmHg}$ postoperatively (Fig. $3 \mathrm{~b}$ ). The cardiac index returned to normal values in the patients in whom it was reduced preoperatively (Fig. 3c).

Selective left ventriculography was performed in each patient in the right anterior oblique view, and this confirmed the clinical findings of com-
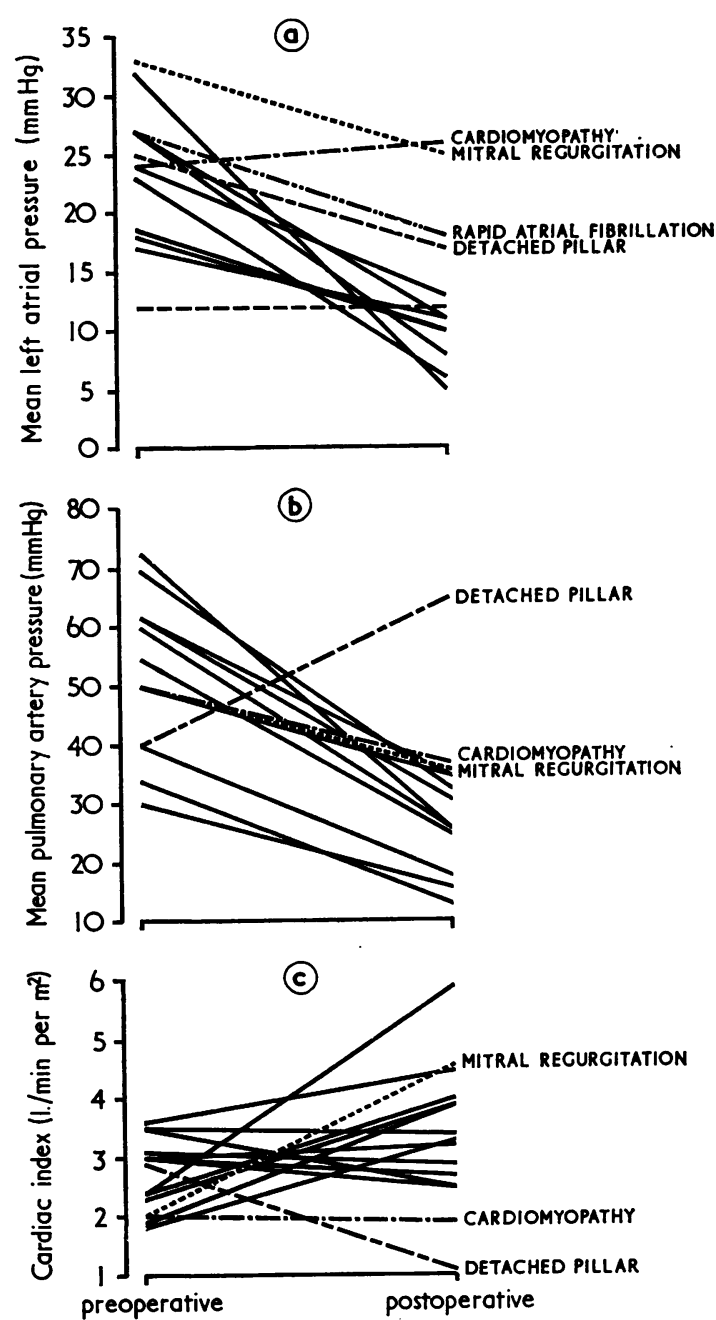

FIG. 3. Postoperative changes in (a) mean left atrial pressure, (b) mean pulmonary artery pressure, and (c) cardiac index.

petent mitral valves, except in one patient in whom a fine jet was visible and interpreted as a ring leak.

FAILURE OF VALVE FUNCTION Failure to return to normal haemodynamics occurred in three patients. J.C., a 42-year-old butcher, returned to a fully active normal life after homograft replacement of the mitral valve for severe calcified mixed mitral valve disease. Thirty weeks after operation he experienced a sudden unpleasant sensation in the chest, followed by breathlessness and generalized weakness, and on palpation of his 
own chest he felt a thrill. Recatheterization three days later (Table, patient 4) showed severe mitral regurgitation, and at operation one pillar of the homograft valve was detached from the frame and this allowed the valve to invert during systole. The defective valve was successfully replaced 32 weeks after initial insertion.

A.P. (Table, patient 12) had been known to have moderate mitral regurgitation since valve insertion, and reinvestigation confirmed this; a left ventriculogram showed regurgitation to occur over a broad front, and it was not possible to decide whether the leak was peripheral or valvular. Re-operation has not yet been undertaken.

M.S. (Table, patient 13) was grade IV disabled with severe mitral regurgitation. Preoperative investigation revealed a left ventricle with considerably increased end-diastolic volume, but with good contraction in all areas, and an area of calcification in the region of the mitral valve. At surgery the calcification was found to be in the left ventricular wall subjacent to the mitral valve, and histological examination of the excised mitral leaflets and left atrial wall did not show evidence of past or present rheumatic activity. Improvement in clinical status did not occur postoperatively, and repeat catheterization 36 weeks after operation showed no significant change in left atrial pressure, a high left ventricular end-diastolic pressure of $22 \mathrm{mmHg}$ (previously $6 \mathrm{mmHg}$ ), a competent mitral homograft, and extremely poor left ventricular contraction on angiography. The cause of the cardiomyopathy remains obscure ; coronary artery disease is not considered a contributory cause since the patient is a 24year-old African man.

The degree and rapidity of radiographic reduction in heart size has been striking, with close correlation between improved haemodynamics and reduction in cardiothoracic ratio (Fig. 4).

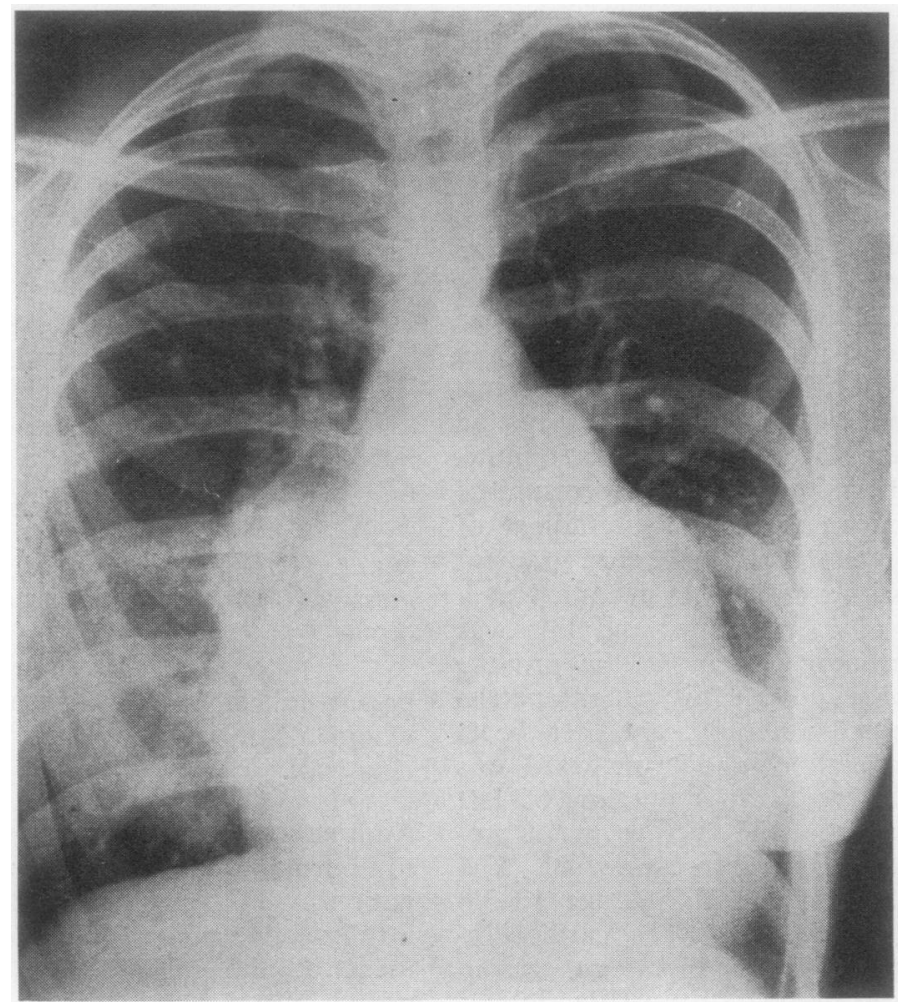

FIG. 4 (a). Legend opposite. 


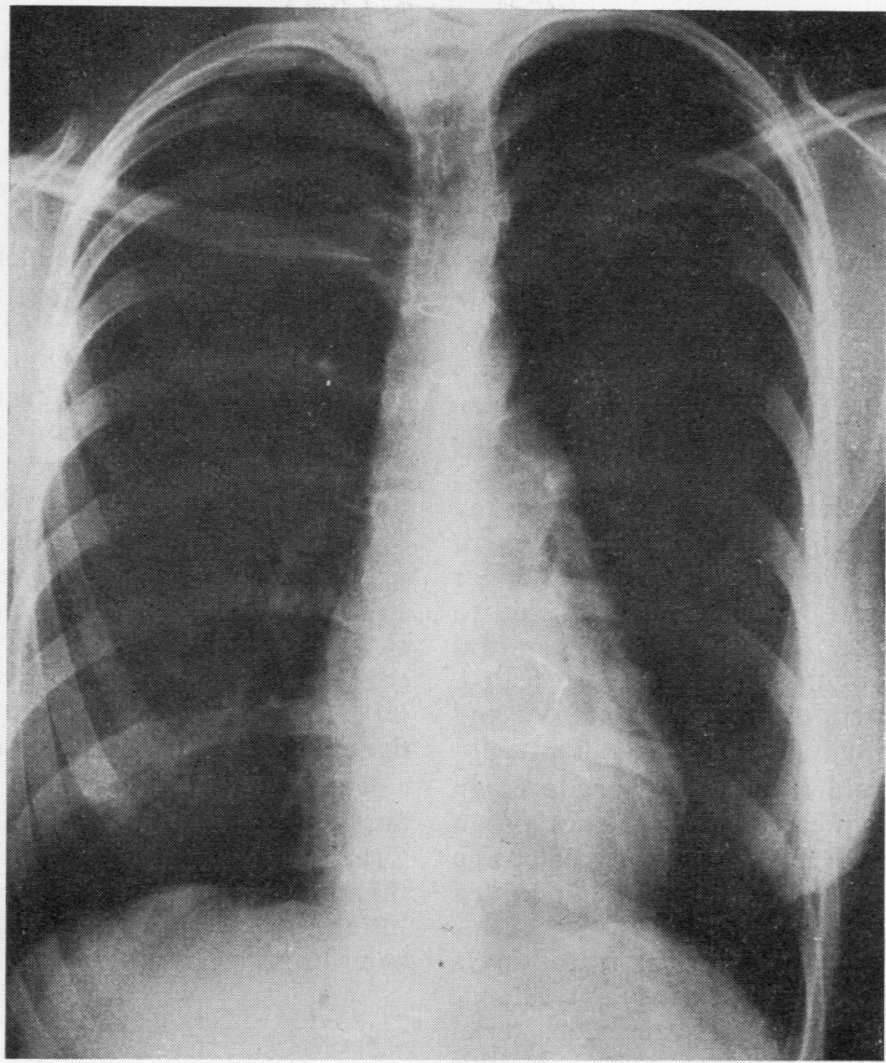

(b)

FIG. 4. Postero-anterior chest radiographs (a) preoperative and (b) six months after homograft aortic valve replacement of the mitral valve. The changes in cardiothoracic ratio and in the upper lobe pulmonary veins are striking.

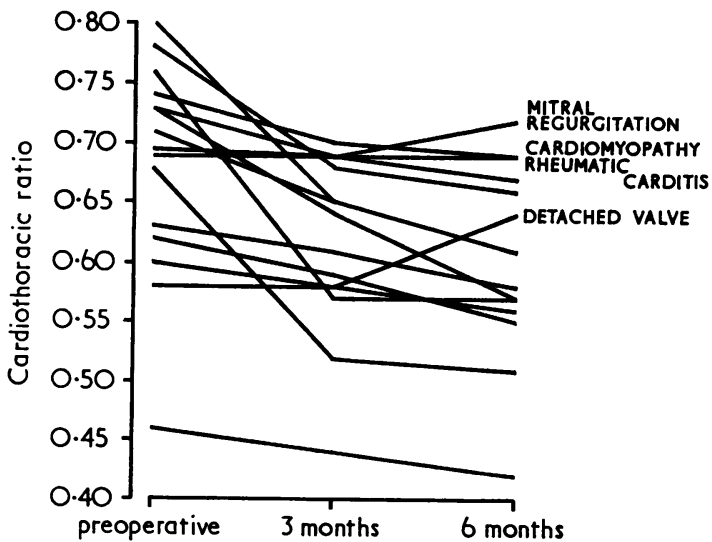

FIG. 5. Changes in cardiothoracic ratio three and six months after homograft valve replacement of the mitral valve in the 15 patients investigated.
Figure 5 shows changes in the cardiothoracic ratio in the 15 patients who were recatheterized three and six months after operation. There has been no change, or only slight improvement, in heart size in the patients with either mitral regurgitation or cardiomyopathy.

\section{DISCUSSION}

Replacement of the mitral valve with a mounted aortic homograft is technically no more demanding than-and the operation mortality is comparable with-mechanical prosthetic mitral valve replacement. Haemodynamic studies show that the aortic homograft valve functions well in the mitral position. Left atrial pressures and pulmonary artery pressures return to normal or near normal levels while the cardiac output increases.

In this series two valves mounted in frames with an internal diameter of $26 \mathrm{~mm}$ were used. 
Both patients were reinvestigated. In one the mean diastolic gradient across the homograft valve was $4 \mathrm{mmHg}$, while the other patient, who has evidence of continuing rheumatic activity, had a mean diastolic gradient of $7 \mathrm{mmHg}$. In neither patient was there an end-diastolic gradient. The average size human aortic valve is thus haemodynamically a satisfactory substitute for a diseased mitral valve.

There is minimal projection of the frame into the ventricular cavity. Correct positioning of the frame prevents any impingement of a leg of the frame on the outflow tract of the left ventricle; subaortic gradients were not demonstrated in any of the patients reinvestigated. The projection of the legs of the frame into the left venticular cavity may give rise to a murmur difficult to differentiate from the murmur of mild mitral regurgitation. In six of the patients reinvestigated, a systolic murmur (strut murmur) was present and all had competent homograft aortic valves.

An intracardiac rigid metal frame produces an area of turbulence which, in the presence of an inert cloth, produces an environment predisposing to infection. Thus it may be that the mounted homografts, when infected, have a prognosis which is not different from that of infection in the mechanical prosthesis (Barney, Williams, Cayler, and Bracken, 1962). However, bacterial endocarditis has not been encountered in this series of patients. Covering an intracardiac metal prosthesis with a porous fabric promotes the ingrowth of autogenous tissue, preventing thrombus formation and promoting incorporation into host tissues (Braunwald and Bonchek, 1967). One patient in this series had a large ball thrombus in the left atrium which left behind a shaggy left atrial wall when evacuated. In this case only were anticoagulants administered and there have been no episodes of thromboembolism.

Significant mitral regurgitation has occurred in two patients. Valve failure occurred in one patient 30 weeks after operation. This was due to a technical fault in mounting the valve, one pillar becoming detached from the frame. There was no evidence of leaflet disruption. In the second patient, mitral regurgitation was present immediately after operation and it was not possible to decide whether it was due to a ring leak or to cusp prolapse.

The homograft works efficiently despite the absence of the sinuses of Valsalva, and early disruption of the inert cusp tissue would be expected if the cusps were not held in a stable position during ventricular filling. In the normal heart, as the ventricle fills, the mitral valve opens rapidly and the incoming jet strikes the apex of the left ventricle, spreads outwards and upwards behind the mitral leaflet, and generates a ring vortex in the expanding ventricle. The leaflets are held in a stable position. As flow through the mitral valve decelerates, the leaflets start to move towards their closed position and the mitral valve is almost closed before ventricular contraction begins (Bellhouse and Bellhouse, 1969). It is likely that the forces produced by ring vortex in the left ventricle and deceleration of flow through the mitral orifice are acting in the presence of mounted aortic homografts in the mitral position.

The clinical results in the 25 patients with an uncomplicated postoperative course have been striking. They are either asymptomatic or class II in the New York Heart Association classification. Rapid reduction in the size of both the left atrium and left ventricle attests to the haemodynamic suitability of the valve.

The initial results with homografts in the aortic position are promising, but extensive longterm studies are not yet available. However, from this initial study it appears that there will be little difference in the durability of orthotopic and heterotopic aortic homograft valves.

\section{REFERENCES}

Angell, W. W., Iben, A. B., Gianelly, R., and Shumway, N. E. (1969). Aortic homografts for mitral valve replacement. Circulation, 39, suppl. 1, p. 39.

, Stinson, E. B., Iben, A. B., and Shumway, N. E. (1968). Multiple valve replacement with the fresh aortic homograft. J. thorac. cardiovasc. Surg., 56, 323.

_, Wuerflein, R. D., and Shumway, N. E. (1967). Mitral valve replacement with fresh aortic valve homograft: experimental results and clinical application. Surgery, 62, 807.

Barney, J. D., Williams, G. R., Cayler, G. G., and Bracken, E. C. (1962). Influence of intracardiac prosthetic materials on susceptibility to bacterial endocarditis. Circulation, 26, 684 .

Barratt-Boyes, B. G., and Roche, A. H. C. (1969). A review of aortic valve homografts over a six and one-half year period. Ann. Surg., 170, 483.

Bellhouse, B. J., and Bellhouse, F. H. (1969). Fluid mechanics of the mitral valve. Nature (Lond.), 224, 615.

Bigelow, W. G., Trimble, A. S., Auger, P., and Wigle, E. D. (1967). Aortic homograft valve replacement of the mitral valve. J. thorac. cardiovasc. Surg., 54, 438. (Addendum. Ibid., 56, 304 (1968).)

Braunwald, N. S., and Bonchek, L. I. (1967). Prevention of thrombus formation on rigid prosthetic heart valves by the ingrowth of autogenous tissue. $J$. thorac. cardiovasc. Surg., 54, 630. 
Hubka, M., Siška, K., and Holec, V. (1967). Replacement of the mitral valve with an aortic valve homograft implanted into the left atrium. $J$. thorac. cardiovasc. Surg., 53, 260.

Ross, D. (1968). Homograft replacement of the aortic valve. Surgery, 63, 382.
Watson, D. A., Pearson, K. W., Cawley, J. C., Rhea, W. G., Donnelly, R. J., and Dexter, F. (1968). Aortic valve replacement with Dacron-supported grafts. Thorax, 23, 621.

Yacoub, M. H., and Kittle, C. F. (1969). A new technique for replacement of the mitral valve by a semilunar valve homograft. J. thorac. cardiovasc. Surg., 58, 859. 